\title{
Doing words with things of the Internet
}

Evelyn Ruppert, Goldsmiths, University of London

September 2018

Forthcoming in Soziale Welt, Sonderband 23 (2018), 1 - 13.

\section{Abstract}

Much of social and political life is now conducted through the Internet and social and power relations are ever more entwined with digital life. How might digital sociology then attend to fundamental sociological questions of power and subjectivity as people variously act through the Internet? There are of course many studies of how the Internet is remaking sociality, social networks, publics, politics, identities, subjectivities, or human-technology interactions. In various ways, they attend to how the Internet is altering relations not only between people but also between people and vast arrangements of sociotechnical conventions that have become part of everyday language, such as tweeting, messaging, friending, emailing, blogging, sharing, and so on. Interpreting the digital data that these 'registers of action' generate and their different forms of subjectivity represent an interpretive challenge for digital sociology and its emerging digital methods. In response to this challenge, I offer a conceptual framing that starts from Bruno Latour's account of 'how to do words with things' to interpret the various ways that subjects 'do words with things of the Internet'. The framing builds on the formulation that when subjects act they perform different subject positions that are composites of obedience, submission, and subversion. I then focus on subjects who perform digital acts by subverting conventions of the Internet to make rights claims and in doing so bring a political subjectivity called the digital citizen into being.

\section{Introduction}

A person takes photos of police officers battering a protester with a baton and shares these via various platforms of the Internet such as Twitter, Facebook and Instagram. The photos are then tagged, aggregated, retweeted, redirected, liked, rated, and reposted, all of which generate various kinds of data that can be captured, repurposed and analysed to inquire about, for example, how social and political relations are formatted by the sociotechnical arrangements of platforms and their entanglements with the formation of issues, controversies, networks and publics. Noortje Marres (2017), in her recent and significant contribution, describes this as a version of digital sociology that enquires into the digital as a societal phenomenon. She argues that it goes beyond interpretations of digital life as representational to instead understand it as involving complex interactions between digital technologies, social research and social life. Such interactions include various forms of participation and social action, which sociologists have traditionally researched through dialogic methods or 'registers of talk' (e.g., interviews and surveys). However, inquiries into 'registers of action', what people do, especially in relation to the generation of digital data analysed by computational social science, represent for Marres a 'lacunae' for digital research. Digital sociologists, she argues, are yet to find ways to empirically combine these ways of knowing and interpretation. 
This is indeed a methodological challenge for digital sociology, but at the same time it is also an epistemological and ontological one. By not attending to this challenge digital sociology risks repeating what classical sociology has been criticised for: treating all subject actions as the same or homologous. Without registers of talk, how then might we interpret the registers of action or the different meanings of what people do when they act through the various sociotechnical arrangements of the Internet? In turn, what kinds of subjects do different acts then produce? Social subjects? Political subjects? Citizen subjects?

These are the key questions I address in relation to digital sociology's move from registers of talk to registers of action. I do so by drawing and building on a theory of digital acts developed in a book co-authored with Engin Isin, Being Digital Citizens (Isin and Ruppert, 2015). Specifically, I elaborate on our citation of Bruno Latour's reversal of John Austin's understanding of 'how to do things with words' to 'how to do words with things'. I outline how Latour performs a material semiotic analysis to consider the subject who acts in relation to things to say something, or to anticipate a later argument, do words with things of the Internet. While the sociotechnical arrangements through which subjects act in his account are not digital, Latour reminds us how the acting subject has long presented an interpretive challenge for sociological research more generally. However, I argue that the subject who acts through the Internet is not the same subject as we have come to know in sociology. I thus take up Latour's proposition to develop a conceptual framing for interpreting the various registers of action that generate data when people do things through the Internet and the modes of subjectivation they perform. Finally, I situate Being Digital Citizens in relation to Science and Technology Studies (STS) and other literatures on the politics of digital technologies and the Internet and suggest how it might address the lacunae of digital research methods.

\section{Doing things with words and doing words with things}

Over twenty years ago, Latour published a chapter titled, 'How to do Words with Things' (Latour, 2000), which reversed the title of a book by John Austin (1962), How to do things with words. Surprisingly Latour does not mention Austin though he does in later writings when he analyses the performativity of legal texts. ${ }^{1}$ He also does not mention Austin's theory of speech acts, which has been influential in understanding speech as a social activity that not merely describes but is performative, that is, it can make things happen, can have force and produce an effect. We do things with words. Nevertheless, of interest to my argument is how Latour reverses Austin's focus on speech to instead consider how we speak through and in relation to things such as materials and technologies. In this way, Latour also contributes to the understanding that what people say and do are social acts, which Austin does not offer. ${ }^{2}$ Latour does this through the example of the Berlin key and considers it in relation to what is now a relatively well-known argument in STS: that the key is not an object but a thing that is part of a chain of associations between materials, rules, conventions and bodies. He writes: 'What is this thing? What's it used for? Why a key with two bits? And two symmetrical bits? Who are they trying to kid?' 3 Through a long narrative Latour describes how operating this key and the particular design of the keyhole that can accommodate it requires an understanding of a complex convention of bolting and unbolting a door that calls upon actions distinct from those to which we are typically 
accustomed to when using a key. It is a convention that is also learned by watching or being told by others how to do it.

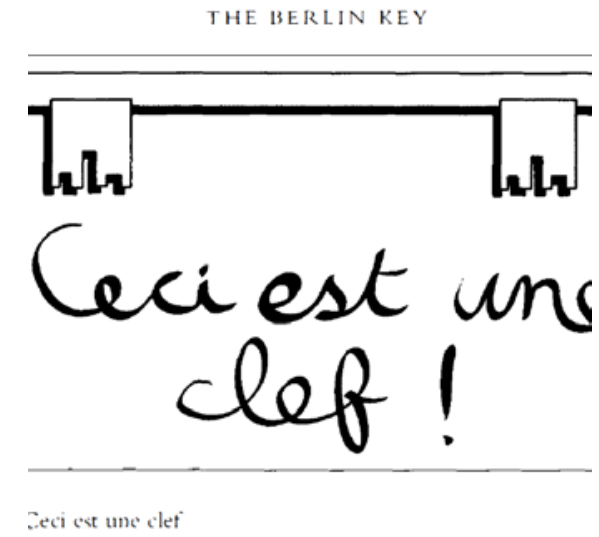

Figure 1: The Berlin Key (Latour, 2000: :11)

What this key does is regulate bolting and unbolting a door according to specific times of the day: it doesn't allow you to bolt a door during certain hours - usually during the daytime - and doesn't allow you to unbolt it - usually during the night hours without re-bolting it otherwise you would not be able retrieve your key from the lock. Through its operation, the key thus regulates passage as well as security and says to the user: 'Please bolt the door behind you during the night and never during the day' (17). How this temporality is regulated is by a concierge who has a special version of this key - a passkey - consisting of one bit only that enables him or her to use it as any other key to bolt and unbolt the door but with one other difference. That action can then enable others to bolt or unbolt it according to either the daytime or night-time convention. That is, his or her action triggers what convention will then be in operation.

At this point in his narrative Latour beams at the possibility of writing how this is a perfect example of collective discipline but then he reveals how some residents file down their keys to remove the two grooves and replicate that of the concierge; he also describes how a concierge doesn't necessarily carry out his or her responsibilities as prescribed. The crux of his narrative is that the key, instead of telling residents through words such as the innumerable notices we often see posted at door entrances in a world of signs that say: 'Please lock the door' - instead words are done with things. But also, he writes that 'The Berlin key, the door and the concierge are engaged in a bitter struggle over control and access' (18).

Latour makes another significant observation: the Berlin key does not speak like any other thing and does not merely transmit a message such as 'lock the door behind you,' which is often the interpretation when mediation is used to describe what things do. That it is a steel key matters and counts for something; it is not just a transmitter:

'Then the meaning is no longer simply transported by the medium but in part constituted, moved, recreated, modified, in short expressed and betrayed. No, the asymmetrical slot of the keyhole and the key with two bits do not 'express', 'symbolise', 'reflect', 'reify', 'objectify', 'incarnate' disciplinary relations, they make them, they form them' (18). 
He goes on to argue that meaning does not come before such technological devices. Things such as the Berlin key are not simply means to an end but can also be at once means and ends. Other things such as signs and norms can seek to regulate the door but in this case we have a thing made of steel that contains morality and law and this difference matters, for it gives the key particular force but only as part of a chain of relations. Alone the key is but provisional; it needs bodies that act and consequently it is fragile too. It can be altered and perform in ways other things cannot and be part of the invention of new conventions.

\section{Doing and subjectivity: performing power}

What Latour, and for that matter Austin, do not conceptualise are the different relations of power that configure how subjects perform through words and deeds and in turn the different subjectivities that spring forth. Latour does though draw attention to the various ways that subjects can and do act in relation to the key and others: they obey, conform or change the key and its conventions to invent new ones that would also apply to others. In this way, he effectively shows that rather than settled and certain, these relations involve ongoing struggles. Yet while acknowledging different forms of subjectivity, how they take shape, form and involve different relations of power is unexamined. Ironically, Latour references Michel Foucault when he offers one interpretation of the Berlin key as being disciplinary but does not carry this through to account for the fragility of discipline in the face of subjects who act otherwise. This is what Foucault's rethinking of the transformation from ancient to modern forms of power provides through his emphasis on the simultaneous presence of three modes of subjectivation: obedience, submission, and subversion. For him the exercise of modern power demands not only subjects that obey and submit but also can engage in 'acts of truth' (Foucault, 1997). Etienne Balibar, taking up Foucault's framing, describes this as the difference between the 'subjectus' and the 'subjectum', that is, the difference between a subject to power and a subject of power. ${ }^{4}$ A subject to power is one who is dominated by and obedient to a sovereign whereas a subject of power is one who is an agent of power even if this requires participating in their own submission. It is through the subject's submission that the possibility of subversion arises. In this way, what Latour describes as the 'fragility' of the Berlin key is the unknowability of the forms of subjectivation to which it will give rise. Subjects of the Berlin key are not already formed and inhabited by external forces bearing down on them but composite subjects of obedience, submission, and subversion where all three are always-present dynamic potentialities.

Balibar described Foucault's contribution as 'the birth of the citizen subject'. ${ }^{5}$ For him, the citizen subject is the actualisation of the potential to subvert. It is a potential and possibility that is mediated in relation to other people and things (the steel of a key, the actions of a concierge) but both the act (filing down one end of a key) and the subject (obedient, submissive and/or or subversive) are not given. They are performed. But whether the act follows or exceeds existing social conventions that organize sets of relations (how to use the key) cannot be known or controlled. This is a point made by Judith Butler (1990) in her innovative take up of Austin's speech acts to theorize gender. It is through citation, repetition, and resignification of a convention that subjects of both submission and subversion are produced and their acts can have performative force. Yet, as Austin also noted, the latter has unpredictable effects; resignification, in the way understood by Butler as a break with conventions, cannot be 
known in advance and as such is unknowable. What Butler describes as the performative force of saying words is what Latour's account of the Berlin key says about the performative force of doing things. This is related to a final point about Latour's account: by modifying the Berlin key and changing its working convention, subjects are, I argue, making a claim; they are saying through their deeds, 'I have a right to leave the door open at other times.' Its performative force depends on its success - the revised key works or another resident reverts the convention and so it can also fail.

It is this point - the possibility of breaking with conventions and do words with things differently - that provides a way to think about how subjects act through the things of the Internet. Like the Berlin key, when subjects act through the Internet they do so in relation to things such as platforms or apps that are part of sociotechnical arrangements of materials, technologies, rules, conventions and bodies. Things are but one element of the Internet which, as Deibert (2009) describes, is an interconnected network of computers (and information and communication technologies (ICTs)) and includes governments, corporations, and organizations such as Internet service providers (ISPs) who own and operate the infrastructures that connect users to the Internet and each other; software such as operating systems, code, and cryptography; and hardware such as routers, switches, cables, transmitters, receivers, and servers. Such infrastructures extends to the myriad people who maintain, operate, and configure them as DeNardis (2012) notes in a useful description of its complexity and layers. Finally, people are embodied subjects who act through these sociotechnical arrangements of conventions, humans, devices, norms, values, affects, laws, ideologies, and technologies.

Like Berlin keys, things of the Internet such as platforms are made up of conventions that people act through as embodied subjects. The Berlin key needs the subject who understands how to operate the key with a turn of their wrist, to exert pressure, and to push open or close a door; some subjects obey and bolt the door at night while others complain but submit. Yet others file down one end of the Berlin key to form a single bit so that the door can remain open when they go out to walk the dog at night. And so too things of the Internet involve and need embodied subjects who understand and know how to act through it; while some may submit and obey conventions, others can also engage in new deployments of conventions and resignify them. Like Berlin keys, subjects are doing words with things that make up the Internet when they download, upload, forward, and block content to when they encrypt and cloak their actions. And like Berlin keys, Internet platforms shape but are reformed and transformed through the repeated actions, demands, interruptions, and resignifications by subjects who do not just follow but also play with and subvert or seek modify their conventions.

What I am suggesting is that Internet platforms are like Berlin keys: they enable subjects to understand and perform in relation to them as social and technical conventions. That is, the platforms of the Internet do not contain and simply enforce social relations nor do people merely follow conventions, but through the Internet they act in relation to things and others and how they do so can be variable - they can obey, submit and/or subvert them. They can perform through things of the Internet that constitute a 'digital act', which has two aspects: the potential subversion of a convention and the making of a rights claim. Both aspects relate to a conception of the citizen advanced in critical citizenship studies, which posits that the citizen is not simply a member of the nationstate as advanced in usual accounts of state-citizen relations. ${ }^{6}$ Instead, I suggest that citizens are subjects who make rights claims and contest existing rules, laws and conventions such that citizenship is a site of contestation. Not only through what they 
say but through what they do through the Internet, citizens can make rights claims such as 'I, we, they have a right to' be anonymous or share and download documents, for example. ${ }^{7}$

This conceptual framing provides a way to interpret the various registers of action when people do things through the Internet and the modes of subjectivation they perform. Like Berlin keys, they can obey or they can make rights claims and in doing so perform as citizens. In this light, the politics of the Internet are not confined to the demands people make in words about how it should operate, but also how they perform in relation to the sociotechnical relations of which they are a part. Much research of course has been undertaken about the politics of and in digital technologies. Rights and subjectivity are often addressed in relation to issues of ethics and consent and the asymmetry of power relations between human subjects and researchers (Metcalf and Crawford, 2016). Others focus on how power relations are part of the making of data that involves dispersed infrastructures, processes, exchanges and relations between social and technological actors. In STS, this has included approaches that invert infrastructures to demonstrate the values, politics and relations that shape and block what people think and do (Bowker and Star, 1999). That work builds on a classic argument in STS that infrastructures are political and 'technology is politics by other means.' ${ }^{\prime}$ Later work has extended this to information or knowledge infrastructures such as algorithms, intelligent devices, and platforms as being fundamentally political. ${ }^{9}$ This work is critical in advancing the argument that infrastructures are not neutral (nor the data they produce) by drawing attention to how politics and power are exercised by designers and then materialised in the workings of infrastructures.

In contrast, another strand of research focuses not on the politics of what the Internet is politically doing to subjects but how subjects variously engage with platforms to do politics. Subjects organise and mobilise political protests (Fuchs, 2014), engage in citizen journalism (Blaagaard, 2013) or forms of digital activism (McCaughey, 2014; Yang, 2009; Tatarchevskiy, 2011), and challenge or hack conventions of the Internet such as copyright laws (Coleman, 2013; Jordan and Taylor, 2004). Activists who engage in anti-surveillance resistance also invoke different technological resistance strategies such that their acts cannot be reduced to one interpretation (Dencik et al., 2016). In these latter examples, subjects do not just follow and obey the conventions and rules of digital technologies but seek to resignify, modify and perform as political subjects in relation to them. What I have suggested is a way to conceive of the political subject of this strand of research and the various forms of subjectivation through which they act and say words by doing things.

\section{Digital sociology and digital acts}

To return to the opening narrative, how then might we interpret the digital acts of subjects who post photos of police brutality? Let's consider two examples of what has come to be called digital activism. Bonilla and Rosa (2015), in their account of how social media was powerful for documenting and challenging episodes of police brutality in Ferguson, Missouri, coined the term 'hashtag activism' to capture how platforms are key in the forging of new political associations and communities. They show how a variety of social media 'tools' were mobilised to document and circulate images of statesanctioned violence and contested media representations of racialized bodies and marginalized communities. Rahimi (2011), reflecting on social media protests in postelection Iran of 2009 , also goes beyond treating social media platforms as 
communication by analysing the myriad ways they are mobilised to enact political dissent. He outlines how organizers used text messaging as well as various social networking sites such as Facebook to organise protests and disseminate news and images. Both accounts resist a separation between 'offline and online' activism and attend to the various ways that politics are not simply limited or enhanced by platforms but emerge from the ways activists invent new forms of political action and creatively transform and reshape them. Importantly, they emphasise that activists do so in the face of conflict and uneven power relations and as forms of resistance to state power.

What the studies implicitly or explicitly contend is that activists or protesters use social media to do politics and it is the content of digital acts - police brutality or state repression - that distinguish them as political. Additionally, political subjectivity exists in the figures of the 'citizen journalist' or 'activist' or 'protester.' However, the conceptualisation I have outlined begins by first defining what is the digital act (the break with a convention) and then asks what form of political subjectivity does it express? The digital act the aforementioned studies describe is what Allan (2013) argues Internet platforms make possible: the act of witnessing and that we may know differently. Julian Assange, a cofounder of WikiLeaks, wrote in an early reflection that, 'every time we witness an act that we feel to be unjust and do not act we become a party to injustice' (Assange, 2006). There are political and ethical aspects to his statement. The political is a judgement on justice and injustice and the ethical the call to act and bear witness. The ethical becomes clearer when Assange further says, '[t]hose who are repeatedly passive in the face of injustice soon find their character corroded into servility.' Subjects, by exercising the capacity to judge, are not merely obedient (or servile) but also subversive. This is because submission to conventions of the Internet requires first judging the terms of one's own submission. Subjects, for example, also post images and use hashtags to spread them to different networks to promote parties, humour or personal events and news. Arguably, these are the very actions and meanings that social media platforms promote and which serve the commercial interests of their owners. Like subjects who follow the expected logics and conventions of the Berlin key, subjects also submit to the expectations and norms of these platforms both in terms of what they do with them and what they say. However, this capacity to submit to the conventions of the Internet opens the possibility of subversion. In this regard, witnessing can be interpreted as subversive in the effort to resignify expected conventions of platforms, to challenge dominant representations of media and state knowledge, and to expose power injustices and abuses. ${ }^{10}$ Witnessing tells us that there are subjects who find it intolerable to witness abuses and misuses of authority and not share them. Witnessing suggests that citizens have a right to know what state and corporate authorities are doing often in their name. WikiLeaks and whistle-blowing, for example, claim this right to know through both the creation of content and its (re)transmission through actions such as tagging, aggregating, redirecting, liking, and reposting. Such acts of witnessing involve political and ethical claims and the right to witness an injustice and share it (so that the world may know); it is in this regard that they bring the political subjectivity of the digital citizen into being in the sense I previously outlined.

While citizenship has often been reduced to membership in the nation-state, as I previously argued, performing as a citizen is not the exclusive property of the nationstate. On the contrary, the nation-state may be a liability for upholding the subject of power as one who exercises the capacity to subvert power relations. Indeed, many 
digital acts are posed against the nation-state's legitimacy on issues such as national security and this has given rise to evermore expressions of 'the right to bear witness' (Allan, 2013). The Internet thus creates openings for citizens to witness and is increasingly part of our political imaginaries, which extend beyond the boundaries of nation-states.

To be sure, witnessing existed before the Internet, however, it has been resignified through new conventions, which have dramatically altered the politics of knowledge and the right to know. It has been resignified in relation to four political questions. The first concerns anonymity and the right to act without being identified. While remaining anonymous on the Internet continues to be a battle, it constitutes a defining political struggle of our time. The second is the velocity of acting through the Internet and the speed at which what someone does can travel. The third concerns the extensity of acting where the number of addressees and destinations possible is overwhelming as are the boundaries, borders, and jurisdictions an act can traverse. The fourth is that of traceability. If it is done on the Internet, an act can be traced in ways that are practically impossible outside the Internet. Some of these attributes of digital acts are arguably like acts performed through other technologies such as the telegraph, megaphone, radio, and telephone. But it is when anonymity, velocity, extensity, and traceability are taken together that digital acts are distinct in terms of both the conventions by which they become possible and the effects that they can produce. This is especially the case with two other kinds of digital acts - hacking and commoning - through which rights claims are also made. They challenge, if not subvert, conventions of the Internet by, for example, circumventing copyright laws and openly creating, sharing and distributing digital objects. ${ }^{11}$ What the resignification of these political questions suggests is that the subject who acts through the Internet is not the same subject as we have come to know in sociology.

However, as Butler has argued, acts can misfire, be misinterpreted, or have no effect. There is no certainty that witnessing will have effects as there are many potential dangers and perils such as co-optation, assimilation, infiltration, taming, blocking, filtering, and so on. At the same time, digital acts also make it possible for subjects do other things through, for example, tagging and aggregating to disseminate, classify, and curate content or, as I have put it, not only doing things with words but doing words with things in ways that resignify political questions of anonymity, extensity, traceability, and velocity: they enable the dissemination of digital content with anonymity at almost instantaneous speed through numerous networks, and leave traces along the way.

In these ways, actions such as liking or sharing, while countable, are simultaneously 'open-ended' such that they 'keep the register of action in suspension' (Marres, 2017: 156). In relation to this unknowability, Chris Kelty notes that multi-interpretations of action are possible and that such multiplicity is key to the functioning of platforms which seek to engage heterogeneous actors ((Kelty, 2012) cited in Marres (2017)). One way of conceiving of that multiplicity and heterogeneity - or the lacunae of digital research between digital traces or registers of action and interpretation - is the framing of political subjectivity I have proposed. It is a conceptualisation that asserts differentiated possibilities of acting and subjectivation such as the political subject who does not simply participate but through her digital acts does words with the things of Internet. Rather than singular, a range of political subject positions and possibilities can 
come into being when subjects act through the Internet. And like political acts of other kinds, this involves ongoing struggles of which an act is a constitutive part.

This framing also responds to Marres' appeal for more 'democratic' forms of participation and in turn knowledge production that are possible in the context of infrastructures that are economically, politically and socially organised (152). She calls for positive accounts through, for example, experiments with alternative methods of data capture, interpretation and interactive research that mobilise digital technologies for 'progressive purposes'. To do so, I have argued, also requires a concept of the political subject who acts in relation to digital technologies rather than simply participates in and interacts with them. Such a conceptualisation is necessary if societies are to be understood not as structures but as outcomes of acts and power relations that are not ontologically equivalent. People are part of changing, challenging and resignifying digital technologies when they act through the Internet and perform a range of subject positions. I have offered a way to conceive of and interpret the registers of action and the data they generate when people perform subject positions that are composites of obedience, submission, and subversion. And, when people subvert conventions of the Internet and make rights claims, I suggest they are performing digital acts and a political subjectivity called the digital citizen.

\section{Acknowledgments}

I am grateful for the feedback and suggestions of the editors and anonymous reviewers and those of Engin Isin, who provided a critical reading and invaluable comments. Funding from a European Research Council (ERC) Consolidator Grant (615588) supported the research and writing of this article.

\section{Notes}

${ }^{1}$ Latour references Austin in his analysis of how legal texts are made up of not declarative but performative statements: Latour B. (2010) The Making of Law: An Ethnography of the Conseil D'État, Cambridge: Polity. In that book, he argues that a weakness of Austin's concept of speech acts is his reliance on grammar and short interactions rather than 'the whole regime of enunciation,' a regime of associations between materials, rules, conventions and bodies that he elaborates through the example of the Berlin key.

${ }^{2}$ However, in relation to Austin, Bourdieu (1993) (Language and Symbolic Power, Massachusettes: Harvard University Press) also argued that words do not have inherent meaning but that it is acquired within specific situations. He argued that speech acts are social acts and draw their meaning not from linguistic forms but from social conventions that make them possible.

${ }^{3}$ In this quote, Latour is imagining an archaeologist considering this key in the future; of this he writes: 'The archaeologist turns the Berlin key over and over in her hands. Because she has been told, she now knows that this key is not a joke, that it is indeed being used by Germans and that it is even used - the detail is important - on the outer doors of apartment buildings. She had certainly spotted the side-travel allowed by the fact that the two bits were identical, and the lack of symmetry in the teeth had struck her. Of course she was aware, because she had been using keys for a long time, of their usual axis of rotation and felt clearly that one of the bits, either one, could serve as a head in order to exert enough leverage to disengage the bolt.' (12) 
${ }^{4}$ This is an interpretation of Balibar's differentiation in: Balibar E. (1991) Citizen Subject. In: Cadava E, Connor P and Nancy J-L (eds) Who comes after the subject? London: Routledge, 33-57.

${ }^{5}$ As noted in Isin and Ruppert (2015). Balibar is the only scholar known to have made this connection.

${ }^{6}$ See discussion in Clarke J, Coll KM, Dagnino E, et al. (2014) Disputing Citizenship. Policy Press.

7 This is a phrasing proposed in Isin and Ruppert (2015). The phrasing captures that citizenship rights are not claimed for one or some but all citizens. As we also note, making claims was not one of the five classes of speech acts that Austin identified as having performative force, which include judgments, decisions, commitments, acknowledgements, and clarifications. We propose claims as a sixth act to account for the rights claims of citizens.

${ }^{8} \mathrm{~A}$ review essay by Rowland and Passoth summarises some of these works and their conceptualisations of the relation between infrastructures and politics: Rowland NJ and Passoth J-H. (2014) Infrastructure and the state in science and technology studies. Social Studies of Science: $1-9$.

${ }^{9}$ For a discussion of examples see Edwards PN, Jackson SJ, Chalmers MK, et al. (2013) Knowledge Infrastructures: Intellectual Frameworks and Research Challenges, Ann Arbor: Deep Blue.

${ }^{10}$ See for example, Dencik L, Arne H and Cable J. (2016) (Towards data justice? The ambiguity of anti-surveillance resistance in political activism. Big Data \& Society 3) and their account of how activists' resistance to state surveillance practices address the implications of data-driven forms of governance in relation to social justice agendas.

11 These acts are elaborated in Isin and Ruppert (2015). 
References

Allan S. (2013) Citizen witnessing: revisioning journalism in times of crisis, Cambridge: Polity Press.

Assange J. (2006) Conspiracy as Governance. Available at: http://goo.gl/4l8lA.

Austin JL. (1962) How to do things with words, Oxford: Oxford University Press.

Balibar E. (1991) Citizen Subject. In: Cadava E, Connor P and Nancy J-L (eds) Who comes after the subject? London: Routledge, 33-57.

Blaagaard BB. (2013) Shifting boundaries: Objectivity, citizen journalism and tomorrow's journalists. Journalism 14: 1076-1090.

Bonilla Y and Rosa J. (2015) \# Ferguson: Digital protest, hashtag ethnography, and the racial politics of social media in the United States. American Ethnologist 42: 1548-1425.

Bourdieu P. (1993) Language and Symbolic Power, Massachusettes: Harvard University Press.

Bowker GC and Star SL. (1999) Sorting Things Out: Classification and its Consequences, Cambridge, Massachusetts: The MIT Press.

Butler J. (1990) Gender Trouble: Feminism and the Subversion of Identity: Routledge.

Clarke J, Coll KM, Dagnino E, et al. (2014) Disputing Citizenship. Policy Press.

Coleman EG. (2013) Coding freedom: the ethics and aesthetics of hacking, Princeton, N.J: Princeton University Press.

Deibert R. (2009) The geopolitics of internet control: Censorship, sovereignty, and cyberspace. In: Chadwick A and Howard PN (eds) Routledge handbook of internet politics. London: Routledge, 323-336.

DeNardis L. (2012) Hidden Levers of Internet Control. Information, Communication \& Society 15: 720-738.

Dencik L, Arne H and Cable J. (2016) Towards data justice? The ambiguity of antisurveillance resistance in political activism. Big Data \& Society 3.

Edwards PN, Jackson SJ, Chalmers MK, et al. (2013) Knowledge Infrastructures: Intellectual Frameworks and Research Challenges, Ann Arbor: Deep Blue.

Foucault M. (1997) Ethics: Subjectivity and Truth. In: Rabinow P (ed) Essential Works of Foucault, 1954-1984 New Press.

Fuchs C. (2014) Social media: a critical introduction, London: SAGE.

Isin E and Ruppert E. (2015) Being Digital Citizens, London: Rowman \& Littlefield International.

Jordan T and Taylor PA. (2004) Hacktivism and cyberwars: rebels with a cause?, London: Routledge.

Kelty CM. (2012) From participation to power. In: Delwiche A and Henderson J (eds) The Participatory Cultures Handbook. New York and London: Routledge.

Latour B. (2000) The Berlin key or how to do words with things. In: Graves-Brown P (ed) Matter, materiality and modern culture. London: Routledge, 10-21.

Latour B. (2010) The Making of Law: An Ethnography of the Conseil D'État, Cambridge: Polity.

Marres N. (2017) Digital Sociology: The Reinvention of Social Research, Cambridge, UK: Polity Press.

McCaughey M. (2014) Cyberactivism on the participatory web. London: Routledge. 
Metcalf J and Crawford K. (2016) Where are human subjects in big data research? The emerging ethics divide. Big Data \& Society 2.

Rahimi B. (2011) The Agonistic Social Media: Cyberspace in the Formation of Dissent and Consolidation of State Power in Postelection Iran. The Communication Review 14: 158-178.

Rowland NJ and Passoth J-H. (2014) Infrastructure and the state in science and technology studies. Social Studies of Science: 1-9.

Tatarchevskiy T. (2011) The 'popular' culture of internet activism. New Media \& Society 13: 297-313.

Yang G. (2009) The Power of the Internet in China: Citizen Activism Online, New York: Columbia University Press. 